\title{
ПСИХИАТРИЧЕСКАЯ ПРАКТИКА
}

УДК 616.895.87:591.23:616.366-002:616.36-002.2-021.144

Для цитирования: Мальцева Ю.Л., Мальцев В.С., Бородюк Ю.Н., Козлова С.М. Параноидная шизофрения, сочетанная с заболеваниями органов пищеварения. Клинический случай. Сибирский вестник психиатрии и наркологии. 2020; 2 (107): 89-95. https://doi.org/10.26617/1810-3111-2020-2(107)-89-95

\section{Параноидная шизофрения, сочетанная с заболеваниями органов пищеварения. Клинический случай}

\section{Мальцева Ю.Л., Мальцев В.С., Бородюк Ю.Н., Козлова С.М.}

Научно-исследовательский институт психического здоровья, Томский национальный исследовательский медицинский центр Российской академии наук (НИИ психического здоровья Томский НИМЦ)

Россия, 634014, Томск, ул. Алеутская, 4

\section{PEЗЮME}

В статье обсуждается клинический случай шизофрении, протекающей на фоне сопутствующей соматической патологии. В качестве клинической иллюстрации описана и проанализирована история болезни пациента с наиболее распространенным сочетанием - шизофрении с болезнями органов пищеварения (хроническим холециститом и персистирующим гепатитом). Авторами представлен анамнез больного, описана терапевтическая тактика, изменение реакции больного с течением времени в ответ на обострение сопутствующей соматической патологии. Показано, каким образом сопутствующая соматическая патология оказывала влияние на особенности клинического течения шизофрении, формирование типа ремиссии и в конечном итоге на процессы социально-общественной адаптации больного. Приводятся принципы фармакотерапии и психотерапевтических вмешательств, направленных на коррекцию субъективных переживаний больного и его ближайшего окружения.

Ключевые слова: шизофрения, заболевания органов пищеварения, персонализированная комплексная фармакотерапия и психотерапия.

\section{ВВЕДЕНИЕ}

Соматическое и психическое здоровье как главная ценность общества определяет вектор актуальных научных исследований. Шизофрения входит в основной реестр ведущих причин инвалидности в мире. Более половины этого контингента больных трудоспособного возраста - инвалиды и безработные, с чем связан высокий уровень инвалидизации. Ещё одна группа риска - это больные шизофренией, имеющие хроническую патологию внутренних органов. В зарубежной и отечественной литературе приводится информация о высокой распространенности сопутствующих соматических заболеваний и указывается, что соматическая отягощенность сокращает продолжительность жизни больных шизофренией. Шизофрения является наиболее тяжелым психическим заболеванием, возникновение и клинические варианты течения которого определяются совокупным взаимодействием генетических и средовых факторов. Наличие сопутствующей соматической патологии является предпосылкой для образования группы труднокурабельных больных шизофренией, лечащихся часто, длительно, с недостаточным эффектом $[1,2,3,4,5,6,7,8]$.
Большинство больных параноидной шизофренией воспринимают госпитализацию как наносящую вред и оппозиционно к ней относятся (к событию, пребыванию и лечению в психиатрическом стационаре). Меньшая часть больных с позитивным отношением к госпитализации признает её эффективность [9].

В качестве иллюстрационного материала нами представлен клинический случай параноидной шизофрении, сочетанной с заболеваниями органов пищеварения - это наиболее распространённое сочетание двух болезней: хронического холецистита и хронического персистирующего гепатита. В основной части приводится анализ клинического наблюдения.

\section{ЦЕЛЬ ИССЛЕДОВАНИЯ}

Изучить влияние сопутствующей соматической патологии на особенности клинического течения частного случая шизофрении, формирование ремиссии и социальной адаптации больного в обществе.

\section{ОБЫЕКТ ИССЛЕДОВАНИЯ}

Пациент Б., 24 года, русский. Проходил стационарное лечение во втором клиническом психиатрическом отделении НИИ психического здоровья со 2 марта по 17 апреля 2020 г. 
Диагноз: шизофрения, параноидная форма, эпизодический тип течения, нарастающий дефект (по МКБ-10 рубрика F20.01).

\section{ОБСУЖДЕНИЕ НАБЛЮДЕНИЯ}

Анамнез. Наследственность манифестными формами психозов не отягощена, однако мать пациента отличается странностью в поведении. По характеру замкнутая, подозрительная, конфликтная, прямолинейная и неуживчивая. Отец больного тихий и спокойный по характеру, после развода проживает отдельно от семьи.

Пациент родился и проживает в г. Стрежевом Томской области. Беременность и роды у матери протекали физиологично, без осложнений. Раннее развитие без особенностей, нейрофизиологическое развитие в норме. Из инфекционных заболеваний в детстве перенес паротит и ветрянку. С 2 лет посещал ясли-сад. В дошкольном возрасте предпочитал проводить время в одиночестве, к контакту со сверстниками особо не стремился, предпочитал общение только с близкими, подолгу любил разглядывать картинки в книгах, собирал конструктор или играл в кубики. Уже в детстве наблюдались некоторые странности в поведении, например, для того чтобы переступить порог комнаты и пойти дальше, считал, что это действие необходимо совершить несколько раз. К 5 годам своеобразная «чудаковатость» самопроизвольно нивелировалась. Рано научился читать и писать. В дошкольном возрасте почти все свое свободное время проводил за любимым занятием - чтением книг. Предпочтение отдавал фантастическим и приключенческим рассказам, мог часами пребывать в мире своих фантазий, где представлял себя героем этих рассказов: «уносился от реальности».

В школу поступил с 7 лет, учился на хорошие и отличные отметки, отличался незаурядным интеллектом и хорошей памятью. Школьный материал давался легко, причем как математические, так и гуманитарные предметы. На досуге по-прежнему увлекался чтением художественной литературы. Отдавал предпочтение произведениям зарубежных авторов (А. Экзюпери, Э. Золя, Ж. Верн), не меньший интерес вызывали произведения русских классиков. В обыденной жизни стремился подражать героям романов: хотел быть справедливым, честным, не курил и не употреблял алкоголь. В старших классах увлекся игрой на гитаре и стал сочинять разные мелодии, свое умение старался не демонстрировать и скрывать, близких друзей не имел, «оставался в тени».
В отношениях с родителями был скрытным, сдержанным, ничего о себе не рассказывал, скрывал даже от близкого окружения внутренние эмоции и тайные желания. В старших класcax (c 15-16 лет) начал чаще болеть разнообразными простудными заболеваниями: ОР3, ОРВИ, тонзиллит, синусит.

В 17-летнем возрасте, будучи учащимся 11го класса, в начале учебного года (сентябрь) впервые стал отмечать сильные болезненные ощущения в области правого подреберья с иррадиацией в спину. Через несколько дней на фоне приема жирной пищи появились тошнота, рвота с ощущением горького привкуса и сухости во рту. В течение месяца находился на лечении в терапевтическом отделении больницы. После проведенного многостороннего обследования (OА крови, мочи на желчные пигменты, БАК-билирубин, трансаминазы, щелочная фосфатаза, белковые фракции, ФГДС, УЗИ желчного пузыря) был выставлен диагноз: обострение хронического холецистита. С этого времени эпизодически, а именно после приема жирной или жареной пищи, беспокоили боли в области правого подреберья.

Конкретных планов на будущее в юношеском возрасте никогда не строил, определенных жизненных целей не имел. После окончания 11 классов успешно сдал экзамены на исторический факультет педагогического университета членам прибывшей в Стрежевой выездной экзаменационной комиссии ТГПУ («по стечению обстоятельств»). Приступив к учебе в вузе, уже с начала 1-го курса стал отмечать слабость, нарушение памяти и концентрации внимания, снижение умственной работоспособности. Признаки переутомления считал последствием перенесенного соматического заболевания. В первую зимнюю сессию сказалось низкое качество учебных знаний в вузе - не сдал экзамен по истории Древнего Востока. Долго не раздумывая, самостоятельно забрал документы и бросил учебу в университете. К родителям не вернулся, в течение года посещал подготовительные курсы с целью дальнейшего поступления на философский факультет. Узнав, что при поступлении на специальность «философия» среди абитуриентов, как правило, большой конкурс, решил параллельно сдавать экзамены на психологический факультет педагогического университета, куда был впоследствии принят на платную форму обучения в связи с тем, что не набрал необходимое количество баллов. 
Психическое состояние стало заметно ухудшаться с весны 2019 г. (19 лет). Начал пропускать занятия, стал грубым, вспыльчивым, адистантным, раздражительным. Непродолжительное время встречался с девушкой. После ссоры с подругой по незначительному поводу перенес истерический припадок («истерика»), громко плакал, необоснованно обвинял всех женщин в душевной черствости, лживости и эгоизме. Несмотря на этот эпизод, сдал сессию на хорошие оценки, летние каникулы провел дома с родителями. Находясь дома, отличался повышенной тревожностью, стал «дерганным», раздражительным, болезненно воспринимал замечания близких, вновь начал негативно и злобно отзываться в адрес всех женщин. Совершил импульсивный поступок, по собственной инициативе отдал деньги другу якобы на медикаментозное лечение от наркомании. Узнав, что друг прервал лечение и сбежал из клиники», сильно переживал по поводу того, что приятель вновь употребляет наркотики. Закрылся в комнате и не разговаривал с матерью. В течение нескольких дней отказывался от приема пищи, в результате нарушение режима питания обострился хронический холецистит, испытывал тошноту, появились боли в животе, была однократная рвота. После уговоров матери начал питаться, принимал таблетированные медикаментозные препараты (но-шпа, фестал), в результате соматическое состояние улучшилось. Однако был малоразговорчивым, задумчивым, находился в пределах дома. В сентябре, вернувшись на учебу в Томск, сообщил матери по телефону, что не хочет учиться, потерял интерес к окружающему. Перестал посещать занятия, все время проводил в закрытой комнате, стал грубым, начал нецензурно ругаться. Все деньги, которые ему выслала мать, истратил на покупку дорогой гитары. Начал слышать внутри головы множественные голоса, которые говорили ему, что нужно делать. Однажды услышал голос своего родного деда из Самары, который якобы велел приехать к нему. В Самару отправился автостопом и под влиянием голосов по пути выбросил гитару и все свои документы на обочину дороги. Когда встретился с матерью, пребывал в неустойчивом настроении с быстрым переходом от слез к смеху. Речь была сумбурная, «заговаривался». Начал обсуждать с матерью глобальные политические проблемы, говорил о кризисе в мире, заявлял, что все вокруг плохо, что может произойти катастрофа.
По настоянию матери обратился в клиники НИИ ПЗ, был госпитализирован в отделение эндогенных расстройств. Психическое состояние на момент поступления квалифицировалось синдромом Кандинского-Клерамбо с псевдогаллюцинаторными переживаниями, бредовыми идеями преследования, воздействия, которые носили острую чувственную окраску. Отмечалось наличие ассоциативных и моторных психических автоматизмов (считал, что окружающие люди, а особенно женщины, хотят ему навредить - «весь мир против», умеют читать его мысли, управляют его действиями и поступками, «меняют настроение»). В течение месяца проводилась медикаментозная терапия средними дозами психотропных препаратов (рисполепт 6 мг/сут, хлорпротиксен 75 мг/сут, циклодол 4 мг/сут) На фоне реализованной персонализированной курсовой терапии психическое состояние значительно улучшилось: редуцировалась психотическая симптоматика, однако сохранялось несколько неустойчивое настроение.

Вместе с тем возникло обострение сопутствующего соматического заболевания - хронического холецистита. Стал жаловаться на боли в области печени и желчного пузыря. В связи с ухудшением соматического состояния был проконсультирован врачом-терапевтом, который при объективном исследовании выявил незначительное увеличение печени с плотным, болезненным краем и болезненностью в зоне желчного пузыря, положительные симптомы Ортнера, Мюсси. После дополнительно проведенного обследования в крови наблюдались умеренный лейкоцитоз, повышение СОЭ, повышение уровня билирубина, а также не характерная ранее активность трансаминаз. Терапевтом был выставлен диагноз: хронический некалькулезный холецистит, хронический персистирующий гепатит в стадии умеренного обострения. Существовала необходимость снижения дозировок психотропных препаратов и назначения дополнительного симптоматического лечения (соблюдение диеты - стол № 5, гепатопротекторы, спазмолитики, применение желчегонных средств). На фоне снижения дозировок психотропных препаратов вновь возникло некоторое ухудшение психического состояния. Стали повторяться фрагментарные псевдогаллюцинаторные переживания, возобновились тревога и волнение, нарушился сон. В результате пребывание пациента в отделении затянулось на 2 месяца. 
После выписки продолжал обучение в педагогическом университете, однако успеваемость заметно снизилась. Поддерживающего психотропного лечения не принимал, у врачатерапевта так же не наблюдался.

В ноябре 2019 г. без наличия очевидных объективных причин вновь ухудшилось психическое состояние. Во время лекций и практических занятий находился в возбужденном состоянии, был нелепым, разговаривал сам с собой вслух. По скорой помощи был госпитализирован в Томскую областную психиатрическую больницу. При поступлении наблюдалось крайне неустойчиво-нестабильное е настроение с немотивированной веселостью, дурашливостью. Статус квалифицировался как полиморфный: с выраженными специфическими расстройствами в ассоциативной сфере, доходящими до разорванности мышления, с наличием псевдогаллюцинаторных переживаний (слышал множественные голоса императивного характеpa), с бредовыми идеями отношения, элементами гебефренического поведения. Выполнял гимнастические упражнения «по собственной системе», характеризовался сексуальной расторможенностью, заявлял, что хочет «лечиться сексом». На фоне лечения (рисполепт 8 мг/сут) психическое состояние улучшилось, однако возникло обострение сопутствующей соматической патологии: хронического холецистита, хронического персистирующего гепатита. Кроме того, в силу актуального психического состояния регулярно нарушал рекомендуемую диету, выдавал бурные реакции на запрет врачей употреблять жирную и жареную пищу. Негативно-подозрительно относился к дополнительному медикаментозному лечению, положительный эффект от него не отмечал. Категорически отказывался от симптоматического лечения, особенно от внутривенных вливаний. В стационаре находился в течение 3 месяцев.

После выписки приступить к учебе не смог и оформил академический отпуск, так как попрежнему сохранялись слабость и быстрая утомляемость. Эпизодически беспокоили тупые, ноющие боли в области печени. Попрежнему нарушал диету, отказывался изменить режим питания и наблюдаться как у врача-психиатра, так и у врача-терапевта, мотивируя это отсутствием эффекта от лечения и тем, что его якобы «закололи». В текущем 2020 г. дважды поступал в психиатрический стационар.
В психическом состоянии наблюдалась параноидная симптоматика, характеризующаяся, в первую очередь, бредовыми идеями воздействия, к которым присоединилась новая тематика - возможность отравления. Считал, что мать и врачи-женщины хотят его «истребить» путем отравления. На фоне психотропного лечения вновь наблюдалось ухудшение соматического состояния, что, в свою очередь, еще больше усугубило его психическое состояние. Бредовая интерпретация касалась происходящих событий, главная фабула - отказ от еды и медикаментозного лечения. В стационаре находился в течение 3 месяцев, была оформлена II группа инвалидности по психическому заболеванию. После выписки проживал с матерью. Контакты были ограничены общением с родственниками и врачом-терапевтом. Жаловался на слабость, боли в животе. Если ранее был категорически против посещений терапевта, то теперь постоянно ходил сдавать анализы, однако от поддерживающей психотропной терапии по-прежнему отказывался, считая, что это наносит «непоправимый вред» здоровью.

Психическое состояние. Выглядит соответственно паспортному возрасту. За внешним видом не следит, неухоженный, одет неопрятно, волосы сальные и растрепанные. Тревожный, неусидчивый, подозрительно и с опаской озирается по сторонам. Движения размашистые, угловатые, характерная шаркающая походка. Предъявляет массу жалоб соматического характера: боли в животе, изжога, тошнота. Считает себя тяжелобольным, а врачей некомпетентными, так как ничего, кроме холецистита, не находят. С заговорщицкой интонацией сообщает, что слышит мужской голос, который якобы утверждает, что врачи скрывают от него правду и хотят его отравить. Со слезами на глазах и в голосе говорит о том, что не складываются отношения с противоположным полом, редко вступает в интимные контакты, потому что девушки «считают меня голубым». В силу загруженности психопатологическими переживаниями на вопросы отвечает после длительной паузы, отмечаются ответы по типу «мимо». В беседе избегает визуального контакта, прислушивается к чему-то. Внутри головы слышит мелодии, песни любимых групп («Металлика», «Алиса»), слышит голоса знакомых и незнакомых людей, которые ведут между собой диалоги. Старается не смотреть телевизор, так как там показывают «странные и необъяснимые вещи». 
Периодически мучают возникающие ощущения, что начинает превращаться в различных животных: волка или бурундука. Этому чувственному впечатлению дает бредовую интерпретацию: «не хочется продолжать жить больным человеком, уж лучше стать здоровым животным». В мышлении отмечались соскальзывания, обрывы мыслей, паралогии, аморфность, амбивалентность.

На фоне комплексной психотропной терапии (рисполепт 8 мг/сут, азалептин 100 мг/сут, циклодол 4 мг/сут) наблюдалось улучшение психического состояния, выражающееся редукцией псевдогаллюцинаторных переживаний, бредовых идей инсценировки, метаморфоза. Однако вновь отмечалось обострение сопутствующей соматической патологии. В связи с этим в психическом состоянии наблюдалось появление эпизодов тревоги и волнения, усиление ипохондрических переживаний. Характеризовался возросшей назойливостью в поведении, требовал проведения дополнительных методов обследования.

\section{ЗАКЛЮЧЕНИЕ}

Таким образом, сопутствующая соматическая патология (в виде болезней органов пищеварения) в значительной степени оказывала влияние на особенности клинического течения и реагирования, формирование ипохондрического типа ремиссии, а в конечном итоге на процессы внутриличностной и социальной адаптации больного. Особенно интересно то, как изменяется с течением времени реакция больного в ответ на обострение сопутствующей соматической патологии. Так, если во время первой госпитализации наблюдается устойчивая анозогностическая позиция пациента, то в дальнейшем она трансформируется в выраженную ипохондрическую реакцию, характеризующуюся фиксацией на собственных ощущениях, сопровождающихся несоответствием между характером предъявляемых жалоб и тяжестью состояния. Кроме того, частые обострения соматического заболевания привносят негативно-специфические особенности в клиническую картину шизофрении. Пациент начинает давать бредовую интерпретацию происходящих событий, расширяя фабулу бреда идеями отравления. Бредовые переживания усиливают его негативное отношение к поддерживающему медикаментозному лечению, затрудняют проведение адекватной психофармакотерапии, удлиняют сроки пребывания в психиатрическом стационаре.
В совокупности всё это приводит к нарушению процесса адаптации и развитию такого типа приспособительной защиты, как «социальная оппозиция», когда восстановление социальных функций возможно лишь на сниженном социальном уровне и только при активной дифференцированной социальной поддержке, применении поддерживающей медикаментозной терапии для смягчения позитивных психопатологических расстройств. Переживаемый внутриличностный конфликт с близким окружением и обществом препятствует полноценному восстановлению социально полезной активности, мотивации и компетенции в учебнообразовательной сфере, а также формированию новых навыков больного.

Целью интегративной психореабилитационной работы являлось смягчение последствий негативного восприятия окружающего мира и самого себя в связи с ипохондрической фиксированностью, разъяснение необходимости соблюдения длительной поддерживающей психотропной терапии. В плане психотерапевтического лечения больной участвовал в сеансах курсовой групповой психотерапии, направленной на коррекцию психоэмоциональной напряженности, дезактуализацию ипохондрического спектра переживаний. Кроме того, с матерью пациента проводилась индивидуальная психотерапевтическая работа с целью разъяснения необходимости оказания психо- и социотерапевтической поддержки и обеспечения специальных условий трудовой реабилитации.

\section{КОНФЛИКТ ИНТЕРЕСОВ}

Авторы заявляют об отсутствии явных и потенциальных конфликтов интересов в связи с публикацией данной статьи.

\section{ИСТОЧНИК ФИНАНСИРОВАНИЯ}

Работа выполнена в рамках темы основного плана НИР «Комплексное исследование клинико-психопатологических закономерностей и патобиологических механизмов формирования и прогредиентности социально значимых психических и поведенческих расстройств с разработкой инновационных методов ранней диагностики, персонализированных стратегий терапии и профилактики» (регистрационный номер AAAA-A19-119020690013-2).

\section{СООТВЕТСТВИЕ ПРИНЦИПАМ ЭТИКИ}

Проведенное исследование соответствует этическим стандартам Хельсинской декларации ВМА и одобрено этическим комитетом НИИ психического здоровья Томского НИМЦ (протокол № 131 от 6 апреля 2020 г. Дело №131/3.2020). 


\section{ЛИТЕРАТУРА/REFERENCES}

1. Leucht S., Burkard T., Henderson J., Maj M., Sartorius N. Physical illness and schizophrenia: a review of the literature. Acta Psychiatr Scand. 2007; 116: 317-333. DOI: 10.1111/j.16000447.2007.01095.x

2. Mustafa M.Z., Schofield J., Mills P.R, Priest M., Fox R., Datta S., Morris J., Forrest E.H., Gillespie R., Stanley A.J., Barclay S.T. The efficacy and safety of treating hepatitis $\mathrm{C}$ in patients with a diagnosis of schizophrenia. Journal of Viral Hepatitis. 2014 Jul;21(7):e48-51. doi: 10.1111/jvh.12234

3. Lally J., al Kalbani H., Krivoy A., Murphy K.C., Gaughran F., MacCabe J.H. Hepatitis, interstitial nephritis, and pancreatitis in association with clozapine treatment A systematic review of case series and reports. Journal of Clinical Psychopharmacology. 2018 October; 38(5). DOI: 10.1097/JCP.0000000000000922

4. Chiu Y.-L., Lin H.-Ch., Kuo N.-Wen., Kao S., Lee H.-Ch. Increased risk of concurrent hepatitis C among male patients with schizophrenia. Psychiatry Res. 2017 Dec; 258: 217-220. DOI: 10.1016/j.psychres.2017.08.036

5. Семке А.В., Ветлугина Т.П., Иванова С.А., Рахмазова Л.Д., Гуткевич Е.В., Лобачева О.А., Корнетова Е.Г. Биопсихосоциальные основы и адаптационно-компенсаторные механизмы шизофрении в регионе Сибири. Сибирский вестник психиатрии и наркологии. 2009; 5(56): 15-20. Semke A.V., Vetlugina T.P., Ivanova S.A., Rakhmazova L.D., Gutkevich E.V., Lobacheva O.A., Kornetova E.G. Biopsychosocial bases and adaptive-compensator mechanisms of schizophrenia in region of Siberia. Sibirskii vestnik psikhiatrii $i$ narkologii - Siberian Herald of Psychiatry and Addiction Psychiatry. 2009; 5 (56): 15-20 (in Russian).

6. Семке А.В., Ветлугина Т.П., Рахмазова Л.Д., Иванова С.А., Счастный Е.Д., Федоренко О.Ю., Лобачева О.А., Гуткевич Е.В., Корнетова Е.Г., Даниленко О.А. Биологические и клиникосоциальные механизмы развития шизофрении (итоги комплексной темы НИР ФГБУ «НИИПЗ» CO PAMH, 2009-2012 гг.). Сибирский вестник психиатрии и наркологии. 2013;4(79): 18-26. Semke A.V., Vetlugina T.P., Rakhmazova L.D., Ivanova S.A., Schastnyy E.D., Fedorenko O.Yu., Lobacheva O.A., Gutkevich E.V., Kornetova E.G., Danilenko O.A. Biological and clinical-social mechanisms of development of schizophrenia (results of complex theme of research work of FSBI "MHRI" SB RAMSci, 2009-2012). Sibirskii vestnik psikhiatrii $i$ narkologii - Siberian Herald of Psychiatry and Addiction Psychiatry. 2013; 4(79): 1826 (in Russian).

7. Семке А.В., Мальцева Ю.Л. Соматические расстройства при шизофрении. Томск : Изд-во «Иван Федоров», 2009: 180. Semke A.V., Maltseva Yu.L. Somatic disorders and schizophrenia. Tomsk : Publishing House «Ivan Fedorov», 2009: 180 (in Russian).

8. Ветлугина Т.П., Лобачева О.А., Найденова Н.Н., Семке А.В. Клинико-динамические аспекты психонейроиммунологии (на модели шизофрении). В книге: Патофизиология психических расстройств / Под научной редакцией В.Я. Семке и Ф. Ланга. Томск, 2006: 143-155. Vetlugina T.P., Lobacheva O.A., Naydenova N.N., Semke A.V. Clinical and dynamic aspects of psychoneuroimmunology (on the model of schizophrenia). In the book: Pathophysiology of Mental Disorders / Under the scientific editorship of V.Ya. Semke and F. Lang. Tomsk, 2006: 143-155(in Russian).

9. Дёгтев В.П. Отношение к госпитализации и приспособительное поведение у больных параноидной шизофренией: автореф. дис. ... к.м.н. СПб., 2008: 27. Degtev V.P. Attitude to hospitalization and adaptive behavior in patients with paranoid schizophrenia: $\mathrm{PhD}$ thesis. St. Petersburg, 2008: 27 (in Russian).

Поступила в редакцию 20.04.2020

Утверждена к печати 01.06.2020

Мальцева Юлия Леонидовна, к.м.н., врач высшей категории, заведующая вторым клиническим психиатрическим отделением.

Мальцев Валерий Сергеевич, к.м.н., врач высшей категории, врач-психиатр первого клинического психиатрического отделения.

Бородюк Юлия Николаевна, врач-психиатр второго клинического психиатрического отделения.

Козлова Светлана Мухамедовна, медицинский психолог консультативно-диагностического отделения, психолог высшей категории.

Мальцева Юлия Леонидовна, ymaltseva@gmail.com 
For citation: Maltseva Yu.L., Maltsev V.S., Borodyuk Yu.N., Kozlova S.M. Paranoid schizophrenia, combined with diseases of the digestive system. Clinical case. Siberian Herald of Psychiatry and Addiction Psychiatry. 2020; 2 (107): 89-96. https://doi.org/10.26617/1810-3111-2020-2(107)-89-95

\title{
Paranoid schizophrenia, combined with diseases of the digestive system. Clinical case
}

\section{Maltseva Yu.L., Maltsev V.S., Borodyuk Yu.N., Kozlova S.M.}

Mental Health Research Institute, Tomsk National Research Medical Center, Russian Academy of Sciences Aleutskaya Street 4, 634014, Tomsk, Russian Federation

\begin{abstract}
The article discusses the clinical case of schizophrenia occurring against a background of concomitant somatic pathology. As a clinical illustration, the patient's medical history with the most common combination, schizophrenia and digestive diseases (chronic cholecystitis and persistent hepatitis), is described and analyzed. The authors present the patient's history, describe therapeutic tactics, the change in the patient's reaction over time in response to an exacerbation of concomitant somatic pathology. It is shown how the concomitant somatic pathology influences the features of the clinical course of schizophrenia, the formation of a type of remission, and, ultimately, the processes of social and social adaptation of the patient. The principles of pharmacotherapy and psychotherapeutic interventions aimed at correcting the subjective experiences of the patient and his immediate environment are given.
\end{abstract}

Keywords: schizophrenia, digestive diseases, personalized complex of pharmacotherapy and psychotherapy.

Received April 08.2020

Accepted June 01.2020

Maltseva Yulia L., PhD, Physician of the Highest Category, Head of the Second Clinical Psychiatric Department, Mental Health Research Institute, Tomsk National Research Medical Center, Russian Academy of Sciences.

Maltsev Valery S., PhD, Physician of the Highest Category, Psychiatrist of the First Clinical Psychiatric Department, Mental Health Research Institute, Tomsk National Research Medical Center, Russian Academy of Sciences.

Borodyuk Yulia N., Psychiatrist of the Second Clinical Psychiatric Department, Mental Health Research Institute, Tomsk National Research Medical Center, Russian Academy of Sciences.

Kozlova Svetlana M., Medical Psychologist, Consultative and Diagnostic Department, Psychologist of the Highest Category, Mental Health Research Institute, Tomsk National Research Medical Center, Russian Academy of Sciences.

Maltseva Yulia L., ymaltseva@gmail.com 